\title{
Ag Functionalized Molybdenum Disulfide Hybrid Nanostructures for Selective and Sensitive Amperometric Hydrogen Peroxide Detection
}

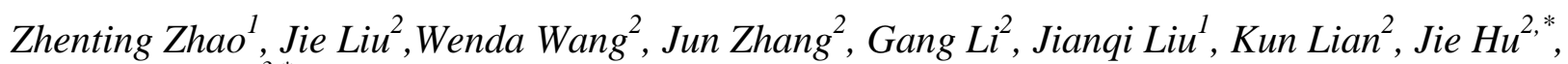 \\ Serge Zhuiykov, \\ ${ }^{1}$ School of Information Engineering, Guangdong Mechanical \& Electrical College, Guangzhou \\ 510515, Guangdong, China \\ ${ }^{2}$ Micro and Nano System Research Center, Key Lab of Advanced Transducers and Intelligent Control \\ System (Ministry of Education) \& College of Information Engineering, Taiyuan University of Technol \\ ogy, Taiyuan 030024, Shanxi, China \\ ${ }^{3}$ Ghent University Global Campus, Department of Applied Analytical \& Physical Chemistry, Faculty \\ of Bioscience Engineering, 119 Songdomunhwa-ro, Yeonsu-gu, Incheon 21985, South Korea \\ *E-mail: hujie@tyut.edu.cn, serge.zhuiykov@ghent.ac.kr
}

doi: $10.20964 / 2017.09 .69$

Received: 6 May 2017 / Accepted: 24 July 2017 / Published: 13 August 2017

Ag nanoparticles functionalized flower-like molybdenum disulfide $\left(\mathrm{MoS}_{2}\right)$ hybrid nanostructures $\left(\mathrm{AgNPs} / \mathrm{MoS}_{2}\right)$ were successfully synthesized by a facile hydrothermal method. The structure and surface morphology were subsequently characterized by scanning electron microscopy (SEM), transmission electron microscopy (TEM), X-ray diffraction (XRD) and X-ray photoelectron spectroscopy (XPS) techniques. The as-synthesized $\mathrm{AgNPs} / \mathrm{MoS}_{2}$ hybrid nanostructures were modified on a glassy carbon electrode (GCE) and further utilized for amperometric hydrogen peroxide $\left(\mathrm{H}_{2} \mathrm{O}_{2}\right)$ detection. The electrochemical behaviors and sensing performance of the $\mathrm{AgNPs} / \mathrm{MoS}_{2} / \mathrm{GCE}$ were studied by cyclic voltammetry (CV) and single-potential amperometry methods. The obtained results have demonstrated that the developed AgNPs/MoS 2 /GCE amperometric sensor possesses an excellent catalytic performance toward the reduction of $\mathrm{H}_{2} \mathrm{O}_{2}$. The as-prepared electrochemical sensor exhibits fast response time of less than $3 \mathrm{~s}$, large linear detection range of 0.025-135.2 $\mathrm{mM}\left(R^{2}=0.998\right)$ and high sensitivity of $54.5 \mu \mathrm{A} \cdot \mathrm{mM}^{-1} \cdot \mathrm{cm}^{-2}$. Moreover, the developed $\mathrm{H}_{2} \mathrm{O}_{2}$ sensor has shown good antiinterference ability, outstanding stability and reproducibility, which represents a great potential for $\mathrm{H}_{2} \mathrm{O}_{2}$ detection in practical applications.

Keywords: Molybdenum disulfide, Silver nanoparticles, Hydrogen peroxide, Electrochemical sensor 


\section{FULL TEXT}

(C) 2017 The Authors. Published by ESG (www.electrochemsci.org). This article is an open access article distributed under the terms and conditions of the Creative Commons Attribution license (http://creativecommons.org/licenses/by/4.0/). 